\title{
CONTROLE DE CONSTITUCIONALIDADE DIFUSO E O SENADO FEDERAL: LETRA MORTA NA CONSTITUIÇÃO OU INCONSTITUCIONALIDADE DAS SÚMULAS VINCULANTES?
}

Jessica Fernanda Alves Cavalcante, Luis Henrique Ramos Alves, Myllena Silva, Shirley Oliveira Lima Nomura

Universidade do Oeste Paulista - Unoeste, Direito, Presidente Prudente, SP. E-mail: luishenrique981@hotmail.com

\begin{abstract}
RESUMO
Para garantir sua supremacia hierárquica no ordenamento jurídico brasileiro, a Constituição Federal, possui o chamado Controle de Constitucionalidade, tal instituto possui várias modalidades, de modo que, vamos dissertar a respeito do Controle Difuso exercido pelo STF e a regra estabelecida pelo artigo $52, \mathrm{X}$, da $\mathrm{CF}$, que aduz que compete ao Senado Federal suspender a execução, no todo ou em parte, de lei declarada inconstitucional por decisão definitiva do Supremo Tribunal Federal. Entretanto esse dispositivo da Constituição vem sendo considerado, por juristas e doutrinadores, como uma "letra morta", visto que a EC no 45/04 instituiu as súmulas vinculantes no artigo 103-A, que vem substituindo referida regra, estabelecendo que o STF poderá, de ofício ou por provocação, após reiteradas decisões sobre matéria constitucional, aprovar súmula. Diante disso fica a dúvida: a Súmula é constitucional e a competência do Senado é letra morta ou a Súmula é Inconstitucional?

Palavras - chave: Controle, Constitucionalidade, Senado Federal, Súmula, Inconstitucionalidade.

DIFFUSE CONTROL OF CONSTITUTIONALITY AND THE FEDERAL SENATE: DEAD LETTER IN THE CONSTITUTION OR UNCONSTITUTIONALITY OF BINDING SUMMARIES
\end{abstract}

\begin{abstract}
In order to guarantee its hierarchical supremacy in the Brazilian legal system, the Federal Constitution has the so-called Constitutionality Control, and such an institute has several modalities, so that we will talk about the Diffuse Control exercised by the STF and the rule established by article $52, \mathrm{X}$, of the $\mathrm{CF}$, which states that it is the responsibility of the Federal Senate to suspend the execution, in whole or in part, of a law declared unconstitutional by a final decision of the Federal Supreme Court.

However, this provision of the Constitution has been considered by lawyers and jurists as a "dead letter", since EC № 45/04 instituted the binding summaries in Article 103-A, which has replaced said rule, stating that the STF may, officio or by provocation, after repeated decisions on constitutional matters, approve the binding summary. Faced with this is in doubt the precedent is constitutional and the competence of the Senate is dead letter or the Precedent is Unconstitutional?
\end{abstract}

Keywords: Control. Constitutionality. Federal Senate. Summary. Unconstitutionality. 


\section{INTRODUÇÃO}

Dentro de um Estado Democrático de Direito há uma Carta Magna suprema as demais normas de dentro do nosso Ordenamento Jurídico, qual seja, a Constituição Federal. Para manter a hierarquia da Constituição dentro do Ordenamento Jurídico, temos o chamado Controle de Constitucionalidade que, de forma bem direta, consiste no mecanismo utilizado para se realizar a fiscalização da conformidade e validade das leis do ordenamento jurídico e, com isso, sempre se buscar à supremacia da Constituição.

O controle de constitucionalidade abrange a modalidade do Controle Difuso, de modo que, dentro desse controle, entendendo o tribunal quanto a inconstitucionalidade de tal norma, possui a faculdade de mandar para o Supremo Tribunal Federal, e este entendendo que a lei é inconstitucional poderá mandar para o Senado Federal ou editar Súmula Vinculantes, a fim de que a decisão seja aplicada aos demais casos concretos. As súmulas vinculantes são entendimentos reiterados de matéria constitucional que após ser aprovada vincula os órgãos do Poder Judiciário e à administração pública direta e indireta, nas esferas federal, estadual e municipal, fazendo com que todos sigam o entendimento sumulado.

O Objetivo do presente artigo é fazer uma análise sobre o controle de constitucionalidade difuso e a atuação do Senado Federal que se tornou estática, buscando resposta para o questionamento "Atuação do Senado Federal, letra morta na Constituição ou Inconstitucionalidade das Súmulas Vinculantes?".

\section{METODOLOGIA}

O Presente artigo foi produzido por meio de um levantamento bibliográfico sobre o Controle de Constitucionalidade, com foco no Controle Difuso, buscando analisar a "letra morta" na constituição e as súmulas vinculantes. Com isso foi utilizado livros, artigos eletrônicos e bibliotecas virtuais. Para o presente artigo foi se utilizado o método hipotético dedutivo, a partir da análise da legislação vigente e doutrina.

\section{RESULTADOS}

Os resultados consistem em que, a própria Constituição ao permitir a edição das súmulas vinculantes às tornou constitucional pois, relativizou seu texto do art. 52, X, (competência do Senado Federal para suspender execução de lei inconstitucional) essa relativização facilitou 0 funcionamento do judiciário e a unificação dos julgados, garantindo ainda mais a justiça no caso concreto.

\section{DISCUSSÃO}

\section{SÚMULAS VINCULANTES}

Diante da constante massa de processos que são submetidos a julgamento no Supremo Tribunal Federal, bem como a quantidade de temas repetitivos que são levados a exame, foi estabelecido, pela Emenda Constitucional n 5/04, o instituto das Súmulas Vinculantes.

As súmulas vinculantes, segundo Alexandre de Moraes (2016, p. 834):

(...) surgem a partir de uma necessidade de reforço à ideia de uma única interpretação jurídica para o mesmo texto constitucional ou legal, de maneira a assegurar-se a segurança jurídica e o princípio da igualdade, pois os órgãos do Poder Judiciário não devem aplicar as leis e atos normativos aos casos concretos de forma a criar ou aumentar desigualdades arbitrárias, devendo, pois, utilizar-se de todos os mecanismos constitucionais no sentido de conceder às normas jurídicas uma interpretação única e igualitária.

Tal instituto, permite ao STF, de ofício ou por provocação, mediante decisão de dois terços dos seus membros, após reiteradas decisões sobre matéria constitucional, aprovar súmula que, a 
partir de sua publicação na imprensa oficial, terá efeito vinculante em relação aos demais órgãos do Poder Judiciário e à administração pública direta e indireta, nas esferas federal, estadual e municipal, bem como proceder à sua revisão ou cancelamento, na forma estabelecida em lei (artigo 103-A, C.F.).

Ainda em seu artigo 103-A, $\S 1$ 으, a Constituição Federal estabelece como objetivo de tal instituto "a validade, a interpretação e a eficácia de normas determinadas, acerca das quais haja controvérsia atual entre órgãos judiciários ou entre esses e a administração pública que acarrete grave insegurança jurídica e relevante multiplicação de processos sobre questão idêntica".

Portanto, as súmulas, nada mais são que, entendimentos consagrados pelo STF, interpretando determinado dispositivo legal a um caso concreto e disciplinando sua aplicação a todas as demais causas similares, de modo que, tal entendimento se torne coercitivo aos demais órgãos do Poder Judiciário e à toda Administração Pública, a fim de evitar decisões conflitantes e desiguais.

\section{CONTROLE DE CONSTITUCIONALIDADE}

O controle de constitucionalidade é o mecanismo utilizado para se fiscalizar a conformidade e validade das leis do ordenamento jurídico à carta magna, de modo a sempre buscar a supremacia da Constituição Federal. Busca-se hoje a plena eficácia da hierarquia da Constituição. De acordo com Alexandre de Moraes (2016, p. 739): “A ideia de controle de constitucionalidade está ligada à Supremacia da Constituição sobre todo o ordenamento jurídico e, também, à de rigidez constitucional e proteção dos direitos fundamentais."

Buscando um conceito para o Controle de Constitucionalidade Moraes (2016, p. 741) aduz que "Controlar a constitucionalidade significa verificar a adequação (compatibilidade) de uma lei ou de um ato normativo com a constituição, verificando seus requisitos formais e materiais".

Esse controle é feito de maneira em que se olhe todas as fases de elaboração da norma, desde o seu início até a sua promulgação, podendo o vício de inconstitucionalidade recair sobre o conteúdo da norma ou até mesmo sobre o seu modo de elaboração. Diante disso possuímos dois pressupostos ou requisitos de constitucionalidade que são os Requisitos Formais e Materiais.

Como Requisito Formal Moraes (2016) nos traz que o controle busca averiguar as regras básicas que devem ser observadas na feitura das espécies normativas. O Requisito Formal se subdivide em Subjetivo e Objetivo. Subjetivo quando o vício de inconstitucionalidade se refere a introdução ao processo legislativo, a iniciativa da norma. Objetiva está relacionado com o trâmite da norma, é necessário observar se a norma passou pelos trâmites descritos pela CF para sua aprovação.

Como Requisito Material Moraes (2016) diz que trata-se da análise da compatibilidade ou não da norma ao texto Constitucional. É dizer que deve-se olhar o que está escrito na Constituição com o que está escrito nas normas infraconstitucionais para ver se são compatíveis e assim, manter a Supremacia da Constituição Federal.

Dentro do Controle de Constitucionalidade temos o Controle Preventivo e o Controle Repressivo, através desses dois mecanismos conseguiremos definir o momento em que é feito o controle.

O Controle Preventivo é aquele realizado antes da norma entrar no ordenamento jurídico, e procura evitar que uma norma que está "contaminada" pelo vício da inconstitucionalidade entre no ordenamento. O controle preventivo é realizado, em via de regra, pela Poder Legislativo através das Comissões de Constituição e Justiça e pelo Poder Executivo, através do Veto Jurídico.

O Controle Repressivo é feito após a norma integrar o ordenamento jurídico, a norma que possui um vício de inconstitucionalidade está dentro do ordenamento jurídico, é necessário realizar um controle para apurar se a norma é ou não é inconstitucional; nos dizeres de Moraes 
(2016, p. 743) "O Controle Repressivo busca dele expurgar a norma editada em desrespeito à Constituição".

O controle repressivo é realizado, via de regra, pelo Poder Judiciário que realiza o controle Difuso e o controle Concentrado e busca retirar do ordenamento jurídico uma lei ou ato normativo contrário à Constituição.

Todavia, excepcionalmente, o controle repressivo é realizado pelo Poder Legislativo através das Medidas Provisória (CF, art.62, §5으), de acordo com Moraes (2016), trata-se das medidas provisórias que são editadas pelo Presidente da República, essas medidas provisórias dentro do ordenamento jurídico possuem vigência e eficácia imediata e fazem força de lei, pelo prazo de 60 dias onde devem ser submetidas ao Congresso Nacional, que poderá aprová-la ou rejeitá-la. Também temos as Delegações (CF, art.49, V), Alexandre de Moraes (2016) nesse caso o Congresso Nacional editará um decreto legislativo sustando ou o decreto presidencial ou a lei delegada, por desrespeito à forma constitucional.

\section{CONTROLE DIFUSO}

O controle de constitucionalidade em sua modalidade repressiva, exercido pelo Poder Judiciário, pode ser realizado de duas formas, tanto de maneira concentrada, quanto de maneira difusa.

No controle de constitucionalidade concentrado, o pedido principal do processo é a inconstitucionalidade de lei ou ato normativo, enquanto que, no controle difuso, o pedido de inconstitucionalidade é analisado de forma incidental, como uma questão prejudicial à análise do pedido principal. Nesta modalidade, o interessado questiona a constitucionalidade da lei ou ato normativo como forma de se eximir do cumprimento do mesmo, quando em desacordo com a Constituição.

A principal característica do controle de constitucionalidade difuso é a permissão à qualquer juiz ou tribunal de declarar a lei ou ato normativo inconstitucional. Não obstante, esta decisão deve respeitar a cláusula de reserva do plenário, ou seja, a inconstitucionalidade somente pode ser declarada pela maioria dos votos dos membros do tribunal ou, onde houver, do órgão especial.

Os efeitos da declaração de inconstitucionalidade quando em sede de controle difuso se dão de duas formas. Primeiramente, a decisão gerará efeitos ex tunc e inter partes, ou seja, entre as partes do processo a decisão alcançará a origem do negócio desfazendo-o, inclusive com todas as consequências decorrentes. Em um segundo momento, quando a decisão de inconstitucionalidade houver sido declarada de forma difusa pelo Supremo Tribunal Federal, este deverá notificar o Senado Federal para que seja editada uma resolução, suspendendo no todo ou em parte a lei ou ato normativo inconstitucional. A partir da publicação dessa resolução, a decisão passará, portanto, a ter efeito erga omnes, e todavia, ex nunc.

$\mathrm{O}$ que muitos doutrinadores e juristas se questionam é quanto a eficácia do art. 52, X, CF, o qual prevê a notificação do Senado Federal pelo STF para a elaboração da resolução, tendo em vista que a EC n45/04, possibilitou que o próprio Supremo Tribunal Federal edite uma súmula vinculante, consolidando assim o entendimento e dispensando a resolução do Senado.

\section{CONTROLE DE CONSTITUCIONALIDADE DIFUSO E O SENADO FEDERAL, LETRA MORTA NA CONSTITUIÇÃO OU INCONSTITUCIONALIDADE DAS SÚMULAS VINCULANTES?}

Como vimos a principal característica do controle de constitucionalidade difuso é a permissão à qualquer juiz ou tribunal de declarar a lei ou ato normativo inconstitucional. Entretanto, esta decisão deve respeitar a cláusula de reserva do plenário. $A$ inconstitucionalidade somente pode ser declarada pela maioria dos votos dos membros do tribunal ou, onde houver, do órgão especial. 
Em via de regra, no controle difuso os efeitos se dão de forma ex-tunc e inter partes, no entanto, quando o tribunal entender que a norma impugnada é inconstitucional e os seus efeitos deveriam Erga Omnes, este possui a faculdade de mandar a norma para o Supremo Tribunal Federal, e entendendo pela declaração de inconstitucionalidade da norma, através do controle difuso, o Supremo Tribunal Federal deverá notificar o Senado Federal, para que seja editada uma resolução suspendendo no todo ou em parte a lei ou ato normativo inconstitucional. Todavia, essa norma da constituição vem sendo considerada pelos juristas e doutrinadores, como Letra Morta, uma vez que, o próprio STF pode editar súmula vinculante e regulamentar a inconstitucionalidade, de modo que, a função dada ao Senado Federal, pelo artigo 52, X, da C.F. tem se tornado inócua. Com isso surge a seguinte pergunta: a Constituição foi relativizada ao permitir a edição de Súmula Vinculante? A Súmula Vinculante é inconstitucional?

Analisando o texto constitucional é possível verificar que a Constituição foi relativizada ao permitir que o STF edite súmula vinculante, ao em vez de mandar para o Senado Federal para a edição da resolução, pois a própria constituição dizia em sua literalidade que deveria mandar para o Senado e a EC 45/2004 trouxe de forma contrária. Com entrada da EC 45/2004 nasceram tais Súmulas Vinculantes e, com base no analisado, acreditamos que tal instituto não é Inconstitucional, uma vez que o próprio Ordenamento Jurídico vem partindo para o Common Low, tendo as Súmulas Vinculantes facilitado o funcionamento do judiciário e a unificação dos julgados, garantindo ainda mais a justiça no caso concreto e até mesmo o Acesso a Justiça de forma eficaz.

\section{CONCLUSÃO}

Através do presente artigo científico conclui-se que, por vezes, é possível relativizar determinado instrumento trazido pela Constituição, sobrestando sua aplicação e, em contrapartida, empregar primordialmente uma nova norma trazida à Carta Magna. No caso em análise vimos que, a EC no 45/04, ao instituir a edição de súmulas nos casos de controle difuso de constitucionalidade, tinha uma finalidade em si, buscando facilitar o funcionamento do judiciário, a unificação de julgados e obstar decisões conflitantes para casos análogos, de modo que, o Acesso à Justiça seja paritário a todos.

Desse modo, o direito como um dos ramos das ciências sociais, tem o homem como objeto de estudo e, consequentemente, nada mais coerente do que acompanhar sua crescente e dinâmica evolução, trazendo institutos mais eficientes para a legislação, ainda que implique em uma relativização e sustação de uma outra norma.

Por fim, ressalta-se que tal relativização não deve ser apontada como inconstitucionalidade das Súmulas Vinculantes, mas o que houve foi que deixamos de aplicar uma norma constitucional, à custa de uma nova interpretação.

\section{REFERÊNCIAS}

LENZA, Pedro. Direito Constitucional Esquematizado. 20.ed. rev., atual. e ampl. São Paulo: Saraiva, 2016.

MORAES, Alexandre de. Direito Constitucional. 32.ed. rev. e atual. - São Paulo: Atlas, 2016.

BRASIL. Constituição da República Federativa do Brasil de 1988. Disponível em: $<$ http://www.planalto.gov.br/ccivil_03/constituicao/constituicaocompilado.htm>. Acesso em: 05/08/2018. 
ORTEGA, Flávia Teixeira. Breve resumo de controle de constitucionalidade - abstrato e difuso. Disponível em: <https://draflaviaortega.jusbrasil.com.br/noticias/306633425/breve-resumo-decontrole-de-constitucionalidade-abstrato-e-difuso>. Acesso em: 04/08/2018.

BIZINOTO, Felipe. O que é o Controle de Constitucionalidade?. Disponível em: <https://felipebpadua.jusbrasil.com.br/artigos/418702861/o-que-e-o-controle-deconstitucionalidade>. Acesso em 04/08/2018.

DOURADO, Rafael. O que são as Súmulas Vinculantes do STF?. Disponível em: $<$ https://constitucionalemfoco.com.br/o-que-sao-as-sumulas-vinculantes-do-stf/>. Acesso em: 05/08/2018.

MARQUES, Gabriel. O que é uma Súmula Vinculante?. Disponível em: <https://gabrielmarques.jusbrasil.com.br/artigos/221414850/o-que-e-uma-sumula-vinculante>. Acesso em: 05/08/2018.

MAURO, Adalgiza Paula Oliveira. Controle de Constitucionalidade Difuso no Brasil e alguns de seus aspectos polêmicos. Disponível em: <http://www.ambitojuridico.com.br/site/index.php?n_link=revista_artigos_leitura\&artigo_id=4937>. Acesso em: 05/08/2018.

MARQUES, Carlos José. A letra morta da Constituição. Disponível em: <https://istoe.com.br/letramorta-da-constituicao/>. Acesso em: 06/08/2018.

OLIVEIRA FILHO, Vergilio Anotnio Ribeiro De. A supremacia constitucional da Súmula Vinculante. Disponível em: <https://jus.com.br/artigos/22255/a-supremacia-constitucional-da-sumulavinculante>. Acesso em: 07/08/2018.

FONSECA. Edson Pires Da. O que é Controle Difuso/Incidental de Constitucionalidade. Disponível em: <http://www.jurisciencia.com/concursos/resumo-o-que-e-controle-de-constitucionalidadedifuso-ou-incidental/1780/>. Acesso em: 08/08/2018. 